\title{
Sixty Years of Hail Suppression Activities in Mendoza, Argentina: Uncertainties, Gaps in Knowledge and Future Perspectives
}

\author{
Juan A. Rivera ${ }^{1,2 *}$, Federico Otero ${ }^{1}$, Elizabeth Naranjo Tamayo ${ }^{1}$ and Martín Silva ${ }^{3}$ \\ 'Instituto Argentino de Nivología, Glaciología y Ciencias Ambientales (IANIGLA), CCT CONICET Mendoza, Mendoza, \\ Argentina, ${ }^{2}$ Instituto de Geotecnologías (IGEO), Universidad Juan Agustín Maza, Mendoza, Argentina, ${ }^{3}$ Facultad de \\ Ingeniería, Universidad Nacional de Cuyo, Mendoza, Argentina
}

\section{OPEN ACCESS}

Edited by:

Paulo Artaxo,

University of São Paulo, Brazil

Reviewed by:

Darrel G. Baumgardner, Droplet Measurement Technologies,

United States

Graciela B. Raga,

National Autonomous University

of Mexico, Mexico

*Correspondence:

Juan A. Rivera

jrivera@mendoza-conicet.gob.ar

Specialty section:

This article was submitted to

Atmospheric Science,

a section of the journal

Frontiers in Environmental Science

Received: 31 January 2020 Accepted: 01 April 2020

Published: 05 May 2020

Citation:

Rivera JA, Otero F, Naranjo Tamayo E and Silva M (2020)

Sixty Years of Hail Suppression Activities in Mendoza, Argentina: Uncertainties, Gaps in Knowledge and Future Perspectives. Front. Environ. Sci. 8:45. doi: 10.3389/fenvs.2020.00045
This paper provides a perspective based on the evaluation of scientific evidence of hail suppression activities in Mendoza, Argentina. The province of Mendoza was home to several cloud-seeding projects over the years intended to prevent hail damage to agriculture. Those projects were motivated by the paramount importance of wine production for the regional and national economy. We discuss the uncertainties and gaps in knowledge identified in the results from the hail suppression activities, framing the available research over the study area on a global context. The results of this study indicate that there is no unequivocal scientific evidence that proves a statistically significant reduction of hail frequency and size as a consequence of hail suppressing activities in Mendoza. Such lack of evidence questions the reliability of the projects after almost 60 years of cloud seeding. By analyzing the existing gaps in knowledge in terms of observations, modeling evaluations and understanding of severe convective systems, the study provides a description of future directions and alternatives for hail damage mitigation that need a better science-policy integration. This study can be replicated in other regions where hail suppressing activities are taking place.

Keywords: weather modification, hail suppression, cloud seeding, agriculture, Argentina, Mendoza

\section{INTRODUCTION}

Hail is one of the most damaging hazards in central-western Argentina, where Mendoza province $\left(32^{\circ} \mathrm{S}, 68^{\circ} \mathrm{W}\right)$ is one of the most hail-prone areas in the world (Rosenfeld et al., 2006). The interaction between the summer atmospheric circulation and regional-to-local mechanisms associated with the complex terrain provides a unique scenario for the development of severe storms over the region, where one of the highest frequencies in flash rates and hail are observed in South America (Mezher et al., 2012; Rasmussen et al., 2014). These storms are also associated with the occurrence of extreme precipitation events that generate flash-floods in urban areas and landslides in mountain areas (Moreiras, 2006; Rasmussen et al., 2014; Vich et al., 2014). Moreover, the occurrence of severe convection strongly affects the cultivated areas -agricultural oases- causing damages and economic losses (Calori et al., 2016). Mendoza province is the main grape-growing region in Argentina, with 70\% of the vineyard area of Argentina and $65 \%$ of the total national grape production (Agosta et al., 2012). 
Given the economic relevance of wine production in the region, hail suppression activities have been conducted, with some interruptions, since 1959 (Dessens et al., 2016), resulting in one of the longest in the world. The main goal of hail suppression is to decrease the frequency of hail occurrences or to decrease the diameter of hailstones and thereby mitigate any potential damage to crops, cars and other material goods (Vujović and Protić, 2017). A variety of aerosols, like silver iodide (AgI), have been used at a local scale for cloud seeding by means of ground generators, aircrafts, and rockets. By seeding hail-bearing clouds with AgI ice-nucleating particles, the number of potential hail embryos might increase, thereby depleting the supercooled water earlier and reducing hailstone size (Gavrilov et al., 2010; Knight et al., 2015). This smaller hail may then melt during its fall before reaching the ground. While these techniques were used in several countries, its effects were very different, even when implementing identical sampling technique and amount of seeding material (Vukelić et al., 2018).

The objective of this study is to make a comprehensive assessment of the scientific evidence available on hail suppressing activities in Mendoza province, Argentina. We focused here only on published articles, book chapters and reviews that statistically quantify the efficiency of the several cloud seeding techniques in hail development over the region. We associated these results to the reported changes in hail frequency over the region during the last 60 years. By comparing these findings with the available information from other regions of the world, we identified several lines of investigation that can contribute to reduce the existing uncertainties and gaps in knowledge in terms of understanding the dynamics of the severe convective systems that generate hail. Thus, the outcomes of this study can provide new directions for the weather modification activities over central-western Argentina.

\section{THE HISTORY OF HAIL SUPPRESSING ACTIVITIES IN MENDOZA}

The first hail suppression project started in 1959, led by the University of Buenos Aires, the National Weather Service of Argentina and the Institute of Agricultural Insurance of Mendoza (Grandoso and Iribarne, 1963). The project was based on randomized seeding with ground generators and the results after 5 years of experiment (1959-1964) indicate that the effects of seeding were non-significant (Dessens et al., 2016). A second phase started in 1974 with the creation of the observation systems and the evaluation of hail impacts, following by the construction of national rocket systems in 1979 and the implementation of AgI as seeding material in 1982 (Sánchez et al., 1998). There is no scientific evidence for the evaluation of hail suppression during this period, although considering that the program was terminated in 1983 due to the lack of confidence in the efficiency of the national rockets, we can infer that results were inconclusive. Soviet rockets were used during the period 1985-1991, guided by two Weather Modification Inc. (WMI) C-band and two MRL-5 S-band meteorological radars installed in the three agricultural oases of Mendoza to support the hail suppression activities (de la Torre et al., 2004). After 1998, aircraft were incorporated to the project, using two types of explosives (cartridges and flares) for cloud seeding (Mulena et al., 2019). Economic difficulties led to changes in the control of the hail suppressing projects, alternating from governmental to private sectors from 1993 to 2004 with some interruptions. Although the meteorological radars were installed for operative purposes, the collected data was occasionally used for scientific research (de la Torre et al., 2004, 2011; Makitov, 2007; Makitov et al., 2017). Similarly, cloud microphysics data was obtained only during short-term experiments with an instrumented aircraft (Rosenfeld et al., 2006). New ground seeding networks have been installed in Mendoza during 2008 to complement aircraft seeding at the foothills of the Andes (Dessens et al., 2016).

\section{CURRENT TRENDS AND LIMITATIONS}

How have hail suppressing activities evolved around the world? To answer that, we used the Scopus search engine using terms such as "hail suppression" "weather modification" and "cloud seeding" as part of the title, abstract and keywords. We selected only the literature published as articles, book chapters or reviews, obtaining a final set of 194 published studies between 1958 and 2019 (see Supplementary Material). The search using similar terms in Spanish did not provided any additional results. Figure 1A shows the distribution of countries involved in the research of hail suppression activities based on the number of papers from their institutions. This graph does not include the studies from institutions with undefined country (79 results). Most of the research was developed by institutions based in countries from North America, Europe, and Asia. Just two published papers were found from Argentinean institutions (de la Torre et al., 2004; Mulena et al., 2019), presenting results non-related to the hail suppressing activities in Mendoza province. Nevertheless, we must consider that some papers analyzing data from Mendoza were published under Russian and Spanish institutions, as well as private international organizations like WMI. Research based on hail suppressing activities around the world was prolific particularly during the second half of the 1970s and the beginning of 1980s (Figure 1B), as part of two major experiments in Western Europe and in the United States that showed statistically non-significant differences in the occurrence of hail between seeded and nonseeded hail bearing clouds (Gavrilov et al., 2013). Many of these activities were purely operational, often without a sound scientific basis (World Meteorological Organization, 2017), and many developed countries have given up on this activity (Gavrilov et al., 2013), factors that are confirmed by the declining trend in the number of published papers per year, with an average of three published papers in the topic during the last 20 years (Figure 1B).

Dessens et al. (2016) indicated that the main difficulty in a hail suppression project is the assessment of the results, which is confirmed in the present study due to the lack of scientific evidence arising from cloud seeding in Mendoza province. Moreover, it is not feasible to separate the natural evolution of deep convection from their possible transformation as a result 

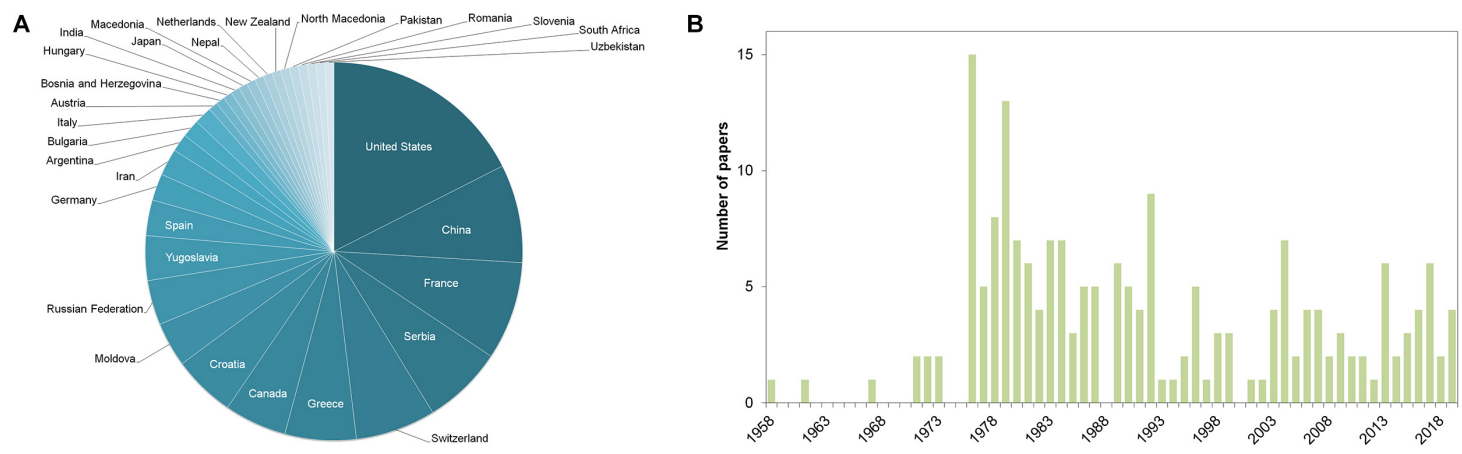

FIGURE 1 | (A) Distribution of the country of origin of the institutions that published research based on hail suppression activities between 1958 and 2019. (B) Temporal evolution of the number of articles published between 1958 and 2019. The criterion for the selection of these studies is described in section "Current Trends and Limitations".

of seeding, neither to perform randomized seeding experiments (Makitov, 1999), factors that complicate the assessment of hail suppression activities in the region. Makitov (1999) compared 11 years with hail suppression activities in the northern area of Mendoza with 13 years without hail protection, finding that hail damages were reduced by $8 \%$ due to cloud seeding. However, this and other publications like Sánchez et al. (1998); Krauss et al. (2000) or Krauss and Mir (2002) have to be questioned due to the potential vested interest by the authors, given that several of them were involved in the activities of private cloud-seeding companies as WMI or Antigrad Latinoamericana. Moreover, we need to point out the existence of scientifically ungrounded annual reports published by both private companies and the Government of Mendoza, which merely describe flight and storm statistics and are overly optimistic about hail reduction in the region.

The results described in the annual reports and in the scientific literature are likely to be affected not only by hail suppressing activities but to climate variability on inter-annual to interdecadal time scales. For example, trends in hail frequency in Mendoza are dependent on the period considered, with historical studies confirming positive trends during the 20th century (Prieto et al., 2001) and non-significant positive trends since the $1960 \mathrm{~s}$ (Mezher et al., 2012), although modulated by periodicities of 4, 8, and 22 years. Thus, the reported increases in hail frequency over Mendoza province - even when non-significant - are contrary to what is expected from hail suppression activities, while there is no evidence for long-term changes in hail size.

If scientists aim to discern about the effectiveness of hail suppression activities in the region, it would be desirable to separate the natural and anthropogenic signals from the temporal variation of hail frequency or size. This is particularly relevant for central-western Argentina, where long-term significant increasing trends in precipitation and temperature were detected (Barros et al., 2015) and inter-annual variability in precipitation was largely attributed to El Niño-Southern Oscillation (Penalba and Rivera, 2016). Prieto et al. $(1999,2001)$ linked the trend in global temperature to the trends in hail occurrences in Mendoza. This was also suggested at a regional scale by Dejanovic et al. (2019) for Bosnia and Herzegovina. Mezher et al. (2012) related hail occurrences with low-level warm anomalies, which are expected to be more frequent in the future over the region (Zazulie et al., 2018).

\section{A CALL FOR AN IMPROVED SCIENCE-POLICY INTERFACE}

The scientific community recognizes the lack in understanding the mechanisms of some of the most intense convective systems of the world, which find the central-western region of Argentina the perfect conditions for its development. International efforts as the RELAMPAGO (Remote sensing of Electrification, Lightning, And Mesoscale/microscale Processes with Adaptive Ground Observations) and CACTI (Clouds, Aerosols, and Complex Terrain Interactions) projects are key for understanding the physical mechanisms causing the initiation and growth of these convective systems. Most of the recent research was focused in convective systems originating in Córdoba province (Repinaldo et al., 2017; Mulholland et al., 2018, 2019; Arias et al., 2019), located $500 \mathrm{~km}$ east of Mendoza. Nevertheless, the RELAMPAGO field campaign also sampled severe storms over Mendoza during late 2018. A recent study from Soderholm et al. (2020) used aerial photogrammetry to measure hail size distribution in central Mendoza, improving the observations based on hail pads. New insights can be expected in the near future from the RELAMPAGO project in terms of the physical basis for understanding hailstorms dynamics over Mendoza.

Currently, the hail suppression program is primarily funded by the Ministry of Economy of Mendoza province. Independent evaluation of the operational cloud seeding activities is required under the provincial law no. 7334, a task that needs to be performed by the National University of Cuyo every 30 days. To our best knowledge, these evaluations are not publicly available, a factor affecting the credibility of the program. The atmospheric science research community, who has the responsibility for basic research and development, is currently not involved in the creation of the annual reports neither in the independent assessment of the hail suppression program. Considering the potential social and environmental impacts of cloud seeding 
activities, particularly on downwind areas, we question if the Secretariat of Environment should not be occupying a more relevant role as control authority. These examples highlight the need for an improved science-policy interface, a topic that was extensively explored over 40 years ago in the United States (Haas, 1973; Borland, 1977; Changnon et al., 1977) and showed promising results more recently in countries as Serbia (Gavrilov et al., 2013). Various interest groups and stakeholders involved in hail suppression activities, as its scientific committee, commercial weather modification firms, and agribusiness organizations, can play a pivotal role in the political decisions regarding the continuity of the hail suppression program.

We identified several lines of investigation that deserve consideration for an improvement in the knowledge of severe convection over the region. Water vapor is crucial for the development of severe convection and hailstorms ( $\mathrm{Li}$ et al., 2019). Nevertheless, the variable is poorly sampled over the study area, with one radiosonde measurement per day. The Global Navigation Satellite System (GNSS) data has been used to retrieve water vapor at both global and regional scales and can be useful for both extreme precipitation and hail forecasting (Calori et al., 2016; Camisay et al., 2020). Modeling studies are by far the most determinant for supporting the activities of hail suppression. Recent studies took advantage of the current computational capabilities to provide a theoretical framework for weather modification, with sensitivity studies evaluating the solubility of natural aerosols (Kovačević, 2019); the influence of cloud droplet concentration on hail suppression effectiveness (Kovačević and Ćurić, 2014) or the effect of different cloud seeding agents (Najafi et al., 2015). The main limitations of these studies are the large computational cost of modeling hail events considering different bulk cloud physics parameterizations and the lack of observations for model validation. The knowledge of the natural evolution of the ice contents within hailstorms is still rudimentary, while the timing and location of seeding materials remain under discussion (Knight et al., 2015). Considering the temporal extension of the hail suppression activities over Mendoza, a large amount of seeding agents can be expected at the ground level during precipitation. This factor can cause negative effects on the human environment if the cloud seeding continues in the future (Ćurić and Janc, 2014) and needs to be properly evaluated.

As identified in section "Current Trends and Limitations," the frequency of hail occurrences over the region is modulated by inter-annual and inter-decadal periodicities linked to factors as El Niño-Southern Oscillation and long-term global warming. It is required to properly isolate the effect of hail suppressing activities from these natural and anthropogenic components to guarantee a feasible evaluation of changes in hail frequency and size as a result of cloud seeding. Since 2004, the Government of Mendoza has adopted a passive protection system based on antihail nets and hail insurance. There is no evidence of the role of these passive systems in the hail damage reduction, neither if its effects are considered while evaluating the effectiveness of the active hail suppressing systems. This factor can potentially contribute to the existence of biases in the annual reports that the Ministry of Economy use to justify to local farmers their success in hail reduction. The study of Gandorfer et al. (2016) can be used as a starting point, which provided evidence for the evaluation of anti-hail nets and hail insurance based on an empirical risk model for Germany. In terms of radar information, an opportunity to update the existing technology is possible due to the development of the First Argentinean Meteorological Radar (Radar Meteorológico Argentino - RMA1). The RMA1 is a dual-polarization C-band Doppler radar that can use open code as the Python ARM Radar Toolkit (Py-ART, Helmus and Collis, 2016) to provide information about size, shape and material density of cloud and precipitation particles (Paulitsch et al., 2009). To determine when and where these radars could be installed is more related to political will than to scientific consensus, another factor to claim for an improved sciencepolicy interface.

\section{FINAL REMARKS}

The central-western Argentina is a region where the interplay between the complex topography and the atmospheric circulation provides unique mechanisms for initiation, intensification and large-scale growth of severe storms. Deep convection is characterized by the occurrence of damaging hail, with yearly losses of about $10 \%$ of the agricultural production (Rosenfeld et al., 2006), a factor that favored the implementation of operational hail suppression programs. In this sense, Mendoza province is the region where the longest hail suppression activities in South America are currently taking place, after almost 60 years of cloud seeding employing ground generators, rockets, and aircrafts. Nevertheless, there is limited scientific evidence to support the hypothesis that cloud seeding can lead to a significant reduction in size and frequency of hail over the region. Documented trends indicate that hail suppression activities in Mendoza do not influence the frequency of hail events, while there is no scientific evidence that supports a decrease of hail size. The findings of this perspective study are in line with the statements of the World Meteorological Organization (2017): there is still uncertainty in the quantitative effects of cloud seeding to enhance precipitation and even more to suppress hail. Moreover, scientific evidence to date is inconclusive and evaluation of the results has proved difficult and the effectiveness remains controversial (Knight et al., 2015).

More than 20 years ago, Matthewman (1998) described the South African scenario in terms of weather modification, where social action was shaped by a set of economic issues, political configurations, and power relations. The very same description can apply to Mendoza province, where livestock farmers and other agricultural stakeholders are becoming increasingly concerned about hail suppression activities over the region. As stated in the evaluation of Hitchsfeld (1973) there should be an agreement between scientists, politicians, civil servants and local farmers to stop routine seeding. Improved knowledge of cloud microphysics and the mechanisms that favor the development of severe convective systems will enable the prediction of these phenomena. This can be achieved by both an increase in observations (based on radiosonde measurements, radars, aircraft, hailpads, disdrometers, and raingauges) and the use of 
cloud-resolving models, with several sets of bulk microphysics parameterization schemes, seeding agents and precipitation processes. If the identified gaps in knowledge will remain or not mainly depends on the consensus of both scientific and politic sectors, given that part of the funding for hail suppressing activities would need to be restructured to support some of the proposed lines of investigation. We finally want to point out that this regional evaluation can be replicated in other regions of the world to have a more comprehensive picture of the state-of-theart of cloud seeding and its effects on hail characteristics.

\section{DATA AVAILABILITY STATEMENT}

All datasets generated for this study are included in the article/Supplementary Material.

\section{AUTHOR CONTRIBUTIONS}

JR, FO, EN, and MS contributed to the design of the study. JR wrote the first draft of the manuscript. FO, EN, and MS provided additional edits to the manuscript. All authors revised and approved the submitted version of the manuscript.

\section{REFERENCES}

Agosta, E., Canziani, P., and Cavagnaro, M. (2012). Regional climate variability impacts on the annual grape yield in mendoza, Argentina. J. Appl. Meteor. Climatol. 51, 993-1009. doi: 10.1175/JAMC-D-11-0165.1

Arias, I., Chandrasekar, V., and Joshil, S. S. (2019). "Cross-validation of CSU-chivo radar and gpm during relampago," in Proceedings of the IGARSS 2019 - 2019 IEEE International Geoscience and Remote Sensing Symposium, Yokohama, 7586-7589. doi: 10.1109/IGARSS.2019.8898835

Barros, V. R., Boninsegna, J. A., Camilloni, I. A., Chidiak, M., Magrín, G. O., and Rusticucci, M. (2015). Climate change in argentina: trends, projections, impacts and adaptation. WIREs Clim. Change 6, 151-169. doi: 10.1002/wcc.316

Borland, S. W. (1977). "Hail suppression: progress in assessing its costs and benefits," in Hail: A Review of Hail Science and Hail Suppression, eds G. B. Foote and C. A. Knight (Boston, MA: American Meteorological Society), $155-175$.

Calori, A., Santos, J. R., Blanco, M., Pessano, H., Llamedo, P., Alexander, P., et al. (2016). Ground-based GNSS network and integrated water vapor mapping during the development of severe storms at the Cuyo region (Argentina). Atmos. Res. 176-177, 267-275. doi: 10.1016/j.atmosres.2016.03.002

Camisay, M. F., Rivera, J. A., Mateo, M. L., Morichetti, P. V., and Mackern, M. V. (2020). Estimation of integrated water vapor derived from global navigation satellite system observations over central-Western Argentina (20152018). Validation and usefulness for the understanding of regional precipitation events. J. Atmos. Solar Terrestr. Phys. 197:105143. doi: 10.1016/j.jastp.2019. 105143

Changnon, S. A., Davis, R., Farhar, B., Haas, J. E., Jones, M., Morgan, G., et al. (1977). Hail Suppression Impacts And Issues. Champaign: Illinois State Water Survey.

Ćurić, M., and Janc, D. (2014). Tendencies for the amounts of chemical material used for cloud seeding in Serbia. Theor. Appl. Climatol. 115, 609-614. doi: 10.1007/s00704-013-0922-0

de la Torre, A., Daniel, V., Tailleux, R., and Teitelbaum, H. (2004). A deep convection event above the tunuyán valley near the andes mountains. Mon. Wea. Rev. 132, 2259-2268.

\section{FUNDING}

This work was supported by the Universidad Juan Agustín Maza (Proyecto convocatoria 2019-2021 "Análisis de eventos extremos de precipitación que afectan la distribución de agua potable en el Gran Mendoza: variabilidad espacio-temporal y forzantes atmosféricos asociados").

\section{ACKNOWLEDGMENTS}

We thank the Instituto Argentino de Nivología, Glaciología y Ciencias Ambientales (IANIGLA) from the National Scientific Research Council of Argentina (CONICET). Results from section "Current Trends and Limitations" were obtained through the Scopus search engine (www.scopus.com). We also thank Dr. Gabriela C. Mulena and two reviewers for their valuable comments and suggestions.

\section{SUPPLEMENTARY MATERIAL}

The Supplementary Material for this article can be found online at: https://www.frontiersin.org/articles/10.3389/fenvs. 2020.00045/full\#supplementary-material

de la Torre, A., Hierro, R., Llamedo, P., Rolla, A., and Alexander, P. (2011). Severe hailstorms near Southern Andes in the presence of mountain waves. Atmos. Res. 101, 112-123. doi: 10.1016/j.atmosres.2011.01.015

Dejanovic, T., Trbić, G., and Popov, T. (2019). "Hail as a natural disaster in Bosnia and Herzegovina," in Climate Change Adaptation in Eastern Europe, eds W. Leal Filho, G. Trbic, and D. Filipovic (Cham: Springer), 245-266.

Dessens, J., Sánchez, J. L., Berthet, C., Hermida, L., and Merino, A. (2016). Hail prevention by ground-based silver iodide generators: results of historical and modern field projects. Atmos. Res. 170, 98-111. doi: 10.1016/j.atmosres.2015. 11.008

Gandorfer, M., Hartwich, A., and Bitsch, V. (2016). Hail risk management in fruit production: anti-hail net versus hail insurance in Germany. Acta Hortic. 1132, 141-146. doi: 10.17660/ActaHortic.2016.1132.19

Gavrilov, M. B., Lazić, L., Pešic, A., Milutinović, M., Marković, D., Stanković, A., et al. (2010). Influence of hail suppression on the hail trend in Serbia. Phys. Geogr. 31, 441-454. doi: 10.2747/0272-3646.31.5.441

Gavrilov, M. B., Marković, S. B., Zorn, M., Komac, B., Lukić, T., Milošević, M., et al. (2013). Is hail suppression useful in Serbia? - General review and new results. Acta Geograph. Slov. 53, 165-179. doi: 10.3986/AGS53302

Grandoso, H. N., and Iribarne, J. V. (1963). Evaluation of the first three years in a hail prevention experiment in Mendoza (Argentina). J. Appl. Math. Phys. 14, 549-553. doi: 10.1007/BF01601262

Haas, J. E. (1973). Social aspects of weather modification. Bull. Amer. Meteor. Soc. 54, 647-657.

Helmus, J. J., and Collis, S. M. (2016). The python ARM radar toolkit (Py-ART), a Library for working with weather radar data in the python programming language. J. Open Res. Softw. 4:e25. doi: 10.5334/jors.119

Hitchsfeld, W. F. (1973). Hail, science and politics. Atmosphere 11, 189-194. doi: 10.1080/00046973.1973.9648361

Knight, C., Knight, N., and Brooks, H. E. (2015). “Mesoscale meteorology | hail and hailstorms," in Encyclopedia of Atmospheric Sciences (Second Edition), eds G. R. North, J. Pyle, and F. Zhang (San Diego, CA: Academic Press), 334-338.

Kovačević, N. (2019). Hail suppression effectiveness for varying solubility of natural aerosols in water. Meteorol. Atmos. Phys. 131, 585-599. doi: 10.1007/ s00703-018-0587-4 
Kovačević, N., and Ćurić, M. (2014). Sensitivity study of the influence of cloud droplet concentration on hail suppression effectiveness. Meteorol. Atmos. Phys. 123, 195-207. doi: 10.1007/s00703-013-0296-y

Krauss, T. W., Bruintjes, R. T., and Martinez, H. (2000). A new hail suppression project using aircraft seeding in Argentina. J. Weather Modif. 32, 73-80.

Krauss, T. W., and Mir, M. M. (2002). Mendoza hail mitigation project final report 2000-2001 - executive summary. J. Weather Modif. 34, 81-83.

Li, Z., Dai, W., Chen, B., and Wen, Y. (2019). "Retrieval of precipitable water vapor using gnss data under conditions without collocated meteorological observations," in China Satellite Navigation Conference (CSNC) 2019 Proceedings, eds J. Sun, C. Yang, and Y. Yang (Cham: Springer), 40-51.

Makitov, V. (1999). Organization and main results of the hail suppression program in the northern area of the province of Mendoza, Argentina. J. Weather Modif. $31,76-86$.

Makitov, V. (2007). Radar measurements of integral parameters of hailstorms used on hail suppression projects. Atmos. Res. 83, 380-388. doi: 10.1016/j.atmosres. 2005.09.016

Makitov, V. S., Inyukhin, V. S., Kalov, H. M., and Kalov, R. H. (2017). Radar research of hailstorm formation and development over the central part of Northern Caucasus (Russia). Organization and main results of the regional hail suppression projects. Nat. Hazards 88(Suppl. 1), 253-272. doi: 10.1007/s11069016-2433-7

Matthewman, S. (1998). Weather-modification in South Africa: public reactions to a 'social science'. Soc. Trans. 29, 104-117. doi: 10.1080/10289852.1998. 10520152

Mezher, R. N., Doyle, M., and Barros, V. (2012). Climatology of hail in Argentina. Atmos. Res. 11, 70-82. doi: 10.1016/j.atmosres.2012.05.020

Moreiras, S. M. (2006). Frequency of debris flows and rockfall along the Mendoza river valley (Central Andes), argentina: associated risk and future scenario. Q. Intern. 158, 110-121. doi: 10.1016/j.quaint.2006.05.028

Mulena, G. C., Puliafito, S. E., and Lakkis, S. G. (2019). Application of tropospheric sulfate aerosol emissions to mitigate meteorological phenomena with extremely high daily temperatures. Environ. Clim. Technol. 23, 14-40. doi: 10.2478/rtuect2019-0002

Mulholland, J. P., Nesbitt, S. W., and Trapp, R. J. (2019). A case study of terrain influences on upscale convective growth of a supercell. Mon. Wea. Rev. 147, 4305-4324. doi: 10.1175/MWR-D-19-0099.1

Mulholland, J. P., Nesbitt, S. W., Trapp, R. J., Rasmussen, K. L., and Salio, P. V. (2018). Convective storm life cycle and environments near the Sierras de Córdoba, Argentina. Mon. Wea. Rev. 146, 2541-2557. doi: 10.1175/MWR-D18-0081.1

Najafi, M., Javanmard, S., and Mohammad-Hosseinzadeh, F. (2015). Comparative study of liquid carbon dioxide and silver iodide seeding effects on cumulonimbus clouds rainfall enhancement and hail suppression. Int. J. Environ. Sci. Technol. 12, 87-104. doi: 10.1007/s13762-014-0667-z

Paulitsch, H., Teschl, F., and Randeu, W. L. (2009). Dual-polarization C-band weather radar algorithms for rain rate estimation and hydrometeor classification in an alpine region. Adv. Geosci. 20, 3-8. doi: 10.5194/adgeo-203-2009

Penalba, O. C., and Rivera, J. A. (2016). Precipitation response to El Niño/La Niña events in Southern South America - emphasis in regional drought occurrences. Adv. Geosci. 42, 1-14. doi: 10.5194/adgeo-42-1-2016
Prieto, R., Gimeno, L., García, R., Herrera, R., Hernández, E., and Ribera, P. (1999). Interannual variability of hail-days in the Andes region since 1885. Earth Planet. Sci. Lett. 171, 503-509. doi: 10.1016/S0012-821X(99)00 170-3

Prieto, R., Herrera, R., Doussel, P., Gimeno, L., Ribera, P., García, R., et al. (2001). Looking for periodicities in the hail intensity in the Andes region. Atmósfera 14, 87-93.

Rasmussen, K. L., Zuluaga, M. D., and Houze, R. A. Jr. (2014). Severe convection and lightning in subtropical South America. Geophys. Res. Lett. 41, 7359-7366. doi: 10.1002/2014GL061767

Repinaldo, H. F. B., Nicolini, M., and García Skabar, Y. (2017). Iniciación de un sistema convectivo sobre las sierras de Córdoba y sensibilidad a modificaciones en el perfil orográfico. Meteorologica 42, 23-42.

Rosenfeld, D., Woodley, W. L., Krauss, T. W., and Makitov, V. (2006). Aircraft microphysical documentation from cloud base to anvils of hailstorm feeder clouds in Argentina. J. Appl. Meteor. Climatol. 45, 1261-1281. doi: 10.1175/ JAM2403.1

Sánchez, J. L., Dessens, J., Dinevich, L., and Simeonov, P. (1998). Hail suppression in Mendoza (Argentina). J. Weather Modif. 30, 79-84.

Soderholm, J. S., Kumjian, M. R., McCarthy, N., Maldonado, P., and Wang, M. (2020). Quantifying hail size distributions from the sky - application of drone aerial photogrammetry. Atmos. Meas. Tech. 13, 747-754. doi: 10.5194/amt-13747-2020

Vich, A. I. J., Rodríguez, M. L., Lauro, C., and Vaccarino, E. (2014). Proposals for flashflood management in Western Argentina. Case study: the metropolitan area of Greater Mendoza. Curr. Urban Stud. 2, 37-48. doi: 10.4236/cus.2014. 21004

Vujović, D., and Protić, M. (2017). The behavior of the radar parameters of cumulonimbus clouds during cloud seeding with AgI. Atmos. Res. 189, 33-46.

Vukelić, G., Cvetković, O., Gržetić, I., Simić, M., Miodragović, Z., Lazić, L., et al. (2018). Anti-hail protection-assessment of financial effects on the territory of Belgrade. Sustainability 10:1239. doi: 10.3390/su10041239

World Meteorological Organization (2017). Executive Council - Sixty-Ninth Session: Abridged Final Report With Resolutions And Decisions. Geneva: World Meteorological Organization.

Zazulie, N., Rusticucci, M., and Raga, G. B. (2018). Regional climate of the Subtropical Central Andes using high-resolution CMIP5 models. Part II: future projections for the twenty-first century. Clim. Dyn. 51, 2913-2925. doi: 10.1007/ s00382-017-4056-4

Conflict of Interest: The authors declare that the research was conducted in the absence of any commercial or financial relationships that could be construed as a potential conflict of interest.

Copyright (c) 2020 Rivera, Otero, Naranjo Tamayo and Silva. This is an openaccess article distributed under the terms of the Creative Commons Attribution License (CC BY). The use, distribution or reproduction in other forums is permitted, provided the original author(s) and the copyright owner(s) are credited and that the original publication in this journal is cited, in accordance with accepted academic practice. No use, distribution or reproduction is permitted which does not comply with these terms. 